\section{Carotenoid Content in Field-grown versus Greenhouse-grown Peppers: Different Responses in Leaf and Fruit}

\author{
Neda Keyhaninejad, Richard D. Richins, and Mary A. O'Connell ${ }^{1}$ \\ Department of Plant and Environmental Sciences, New Mexico State University, \\ MSC 3Q, P.O. Box 30003, Las Cruces, NM 88003
}

Additional index words. Capsicum annuum, carotenes, chlorophyll, pro-vitamin A, xanthophylls, fruit quality

\begin{abstract}
The carotenoid content of fresh fruits, like chiles or peppers (Capsicum annuum L.), is a desirable fruit quality trait because these compounds increase the nutritional value of the fruit. Carotenoids in general serve as antioxidants, whereas specific carotenoids are pro-vitamin $A$ types and yet others are necessary for retinal pigments. In the plant, carotenoids function to harvest light energy during photosynthesis, act as antioxidants in multiple cell types, and pigment fruit and flowers to attract pollinators and seed dispersal agents. All of these cells presumably accumulate carotenoids through the same biosynthetic pathway. We investigated the relationship between light levels in the growth environment and the carotenoid levels that accumulated in mature fruit and leaves. Three chile cultivars with orange fruit, 'Fogo', 'Orange Grande', and 'NuMex Sunset', were grown under three different light conditions, shaded greenhouse, unshaded greenhouse, and field in Las Cruces, NM. Foliar carotenoid increased approximately twofold with increased light, whereas carotenoid content in fruit decreased two- to threefold with increased light. All cultivars showed identical trends with light despite having cultivar-specific carotenoid accumulation patterns in their fruit.
\end{abstract}

Fruits and vegetables are important for human health; people with diets low in fruits and vegetables are more likely to have chronic diseases (Rao and Rao, 2007). Furthermore, dietary fruits and vegetables, rich in antioxidants, are highly recommended. Cellular damage, associated with aging, chronic diseases, and cancers often caused by free radicals, can be prevented with antioxidants (Ames et al., 1993; Valko et al., 2007).

Carotenoids are lipid-soluble pigments that are synthesized in plants, algae, fungi, and bacteria. Specific carotenoids are orange, yellow, and red pigments present throughout the plant and in high concentrations in certain fruits and vegetables (reviewed in Farre et al., 2010). Carotenoids play a key role in photosynthesis; in the pigment-protein complex of photosystems, they have an essential role for harvesting light energy and transferring the energy to chlorophyll (Malkin and Niyogi, 2000). Carotenoids are responsible for the color of many fruits and flowers; these pigments are important for attracting pollinators and seed dispensers.

Received for publication 8 Mar. 2012. Accepted for publication 3 May 2012

This work was supported in part by the New Mexico Agricultural Experiment Station, USDA CSREES NIFA grant 2010-34604-20886.

We are grateful to P.W. Bosland, NMSU, for Capsicum fruit and seed, R. St. Hilaire for loan of the light meter, and M. Mohseni Moghadam for help with the statistical analysis.

${ }^{1}$ To whom reprint requests should be addressed; e-mail moconnel@nmsu.edu. leaves (Simkin et al., 2003). However, the accumulation of carotenoids in Capsicum fruit does not always increase with increasing light. Russo and Howard (2002) showed that seven of 10 red-fruited cultivars of $C$. annuum increased total carotenoid accumulation in fruit when grown under greenhouse conditions relative to the field. Lee et al. (2005) report increased levels of lutein and zeaxanthin in Capsicum fruit grown in a greenhouse vs. two different field settings. Light levels were $\approx 20 \%$ reduced in the greenhouse setting.

In this study, we investigated the role of light on carotenoid content in three orangefruited $C$. annuum cultivars known to have unique carotenoid profiles (Guzmán et al., 2010). We compared the carotenoid accumulation in leaf and fruit tissues of these cultivars in plants grown under three different light levels to evaluate the role of light in two different developmental contexts.

\section{Materials and Methods}

Plant materials. Three cultivars of $C$. annuum, 'Fogo', 'NuMex Sunset', and 'Orange Grande', were grown from seed in a greenhouse on the New Mexico State University (NMSU) campus in Las Cruces, NM, Summer 2010. Seedlings were transplanted to 4-inch pots with MetroMix 360 irrigated daily with a drip system and fertilized with Osmocote (14N-14P-14K). When the plants started to develop fruit, each cultivar was split into two groups of six plants each; one group was moved to a shaded bench in the greenhouse under two layers of a sheer voile white curtain (Mainstays Curtains; Wal-Mart, Bentonville, AR) that decreased light intensity $\approx 40 \%$ to $50 \%$. The other group was kept in an unshaded area of the greenhouse. These same cultivars were planted in the Chile Demonstration Garden, Summer 2010, at the NMSU Fabian Garcia Science Center, Las Cruces, NMSU. Seedlings were started in a greenhouse at the center and transplanted into the garden several weeks later, sown in trays early March, and transplanted into the field mid-April. Mature fully ripened fruits from each cultivar within each group (field, unshaded greenhouse, and shaded greenhouse) were harvested, pericarps dissected, and frozen in liquid nitrogen. Mature fully expanded leaves (10 g) were harvested at the same time as the fruit harvest for carotenoid and chlorophyll extraction.

Chemicals. Purified standards for capsanthin, capsorubin, $\beta$-cryptoxanthin, violaxanthin, and zeaxanthin were obtained from CaroteNature, Lupsingen, Switzerland; $\beta$-carotene, chlorophyll A, and lutein were obtained from Sigma-Aldrich, St. Louis, MO. All other chemicals were HPLC or American Chemical Society reagent grade.

Light measurement. The light intensity was measured using a LI-250 light meter (LI-COR, Lincoln, NE) at the canopy level. In the field, readings were taken at several locations at $1030 \mathrm{HR}$ twice a week for 30 $\mathrm{d}$ before the fruit harvest (1 Aug. to 30 Aug.). In the greenhouse, readings were taken at $1030 \mathrm{HR}$ twice a week at the canopy level of 

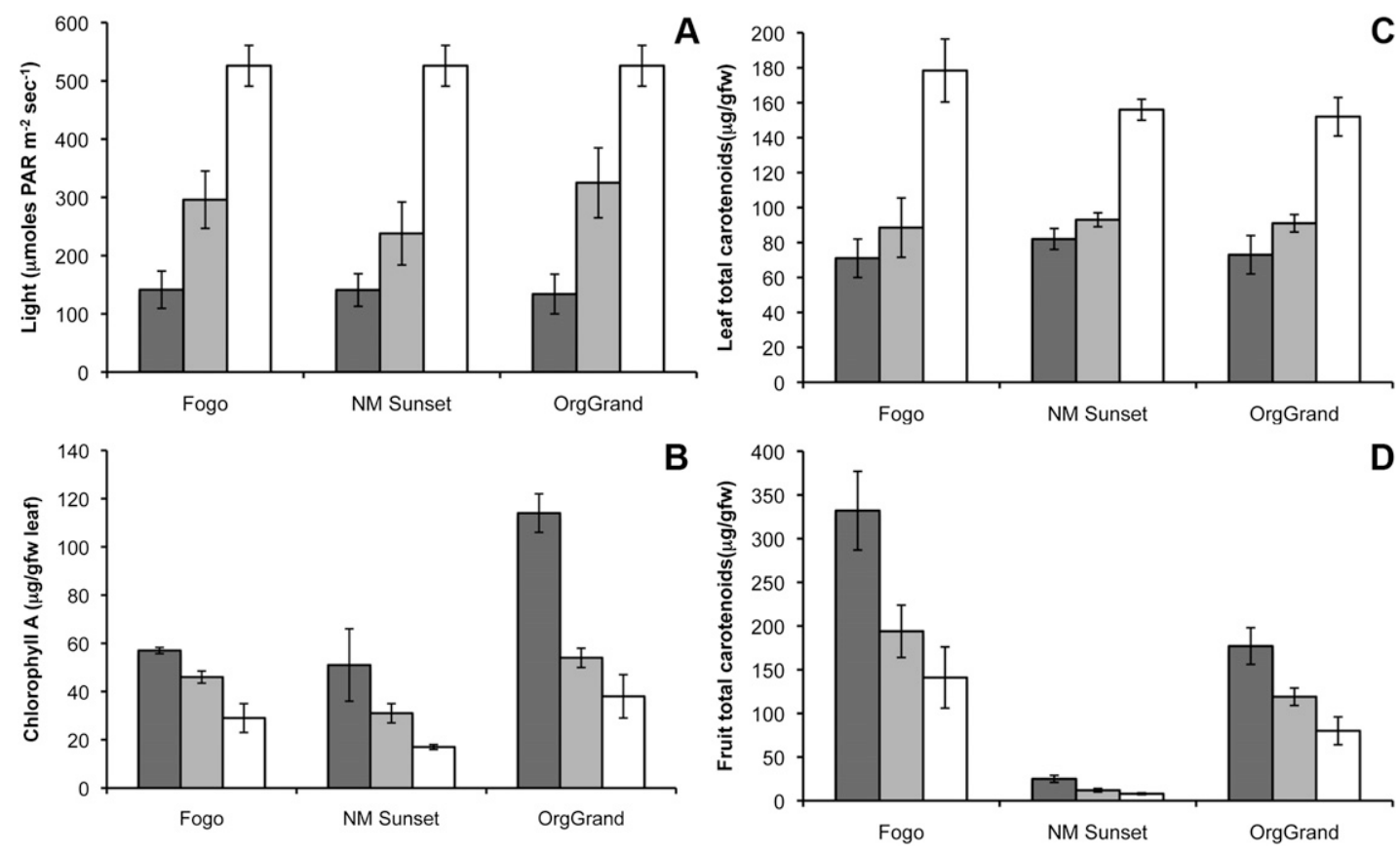

Fig. 1. Pigment accumulation in leaves and fruit of cultivars Fogo, NuMex Sunset, or Orange Grande (OrgGrand) under different illumination conditions: field grown (open bars), unshaded greenhouse (light gray bars) or shaded greenhouse (dark grey bars). (A) Light intensity, photosynthetically active radiation $\left(\mu \mathrm{moles} \cdot \mathrm{m}^{-2} \cdot \mathrm{s}^{-1}\right)$; average \pm SD. (B) Leaf chlorophyll A. (C) Leaf total carotenoids. (D) Fruit total carotenoids. All pigment concentrations expressed as $\mu \mathrm{g} \cdot \mathrm{g}^{-1}$ fresh weight pericarp or leaf, average $\pm S D, n=4$.

each plant for $60 \mathrm{~d}$ before fruit harvest $(10$ May to 10 July).

Extraction and analysis. Pigments were extracted and analyzed essentially as described earlier (Richins et al., 2010; RodriguezUribe et al., 2012). Briefly, fruit or leaf samples, 4 or $8 \mathrm{~g}$, respectively, were extracted with hexane and dried under $\mathrm{N}_{2}$ gas flow, resuspended in isopropanol, and $500 \mu \mathrm{L}$ was saponified with $100 \mu \mathrm{L}$ methanolic $\mathrm{KOH}$ for $30 \mathrm{~min}$ at $50{ }^{\circ} \mathrm{C}$. Water $(500 \mu \mathrm{L})$ and chloroform $(300 \mu \mathrm{L})$ were added to the saponified extract, and the organic phase containing the saponified pigments was collected by centrifugation. Extracts were analyzed on a Waters HPLC system equipped with a $4.6 \times 250-\mathrm{mm}$ YMC carotenoid column. A linear gradient consisting of methanol:methyl-t-butyl ether: water:: 81:15:4 (Solvent A) and methyl-t-butyl ether:methanol:water::88:8:4 (Solvent B) was used. The flow rate was $2 \mathrm{~mL} \cdot \mathrm{min}^{-1}$ at $25^{\circ} \mathrm{C}$. Absorbance data were collected with a photodiode array (PDA) from 400 to $600 \mathrm{~nm}$. Calibration curves were generated at $450 \mathrm{~nm}$ with the reference standards: $\beta$-carotene, lutein, and lycopene (Sigma); and capsanthin, capsorubin, zeaxanthin, antheraxanthin, violaxanthin, and $\beta$-cryptoxanthin, CaroteNature $\mathrm{GmbH}$ (Lupsingen, Switzerland). Hexane extracts before saponification were analyzed to measure chlorophyll content; chlorophyll A peak was detected by absorbance at $432 \mathrm{~nm}$. Quadruplicate extractions were performed on each genotype grown in each of the three environments and the average concentration for each carotenoid and total carotenoids was calculated following independent HPLC analyses.

Statistical analysis. Mean values and SDS of carotenoid accumulation were calculated for each pigment and three different light intensity levels for three cultivars used in this experiment. The Proc General Linear Models procedure in SAS (SAS 9.2; SAS Institute Inc., Cary, NC) was used to determine if there were any carotenoid accumulation differences among different light intensity groups of the same variety in fruits and leaves. The mean for individual and total carotenoids was calculated using the "Proc Means" command in SAS. Carotenoid mean differences among different light intensity groups of the same variety in fruits and leaves were determined with Fisher's least significant difference test at a probability level of 0.05 .

\section{Results and Discussion}

Three environments, one field and two greenhouse settings with distinct light levels, were used to establish three different light levels. Plants in the field were cultivated under light almost four times higher than the group with lowest light intensity, shaded greenhouse plants (Fig. 1A). Average photosynthetically active radiation $(P A R)$ at midmorning for the shaded plants was 139 umoles $\cdot \mathrm{m}^{-2} \cdot \mathrm{s}^{-1} P A R$, whereas the field plants were illuminated at $525 \mu$ moles $\cdot \mathrm{m}^{-2} \cdot \mathrm{s}^{-1} P A R$ with unshaded greenhouse plants receiving an intermediate level at $286 \mu \mathrm{moles} \cdot \mathrm{m}^{-2} \cdot \mathrm{s}^{-1}$ $P A R$. These light levels were associated with different plant pigment accumulations in the leaves and fruit.

Leaf carotenoids accumulate in chloroplasts with most pigment accumulation in the form of chlorophyll-carotenoid-protein complexes. These complexes work as an antenna to harvest light for photosynthesis (Malkin and Niyogi, 2000). As expected, the chlorophyll level of leaves in all three cultivars grown under shaded conditions was higher compared with the chlorophyll level when those cultivars were grown under field conditions (Fig. 1B). There were cultivar-specific differences in the absolute amount of chlorophyll; 'Orange Grande' had higher levels of chlorophyll than the other two cultivars, but within each cultivar, chlorophyll levels increased in leaves as light levels decreased. These same higher light levels were correlated with increased carotenoid accumulation in leaves; again the same pattern was observed for all three cultivars (Fig. 1C).

For field-grown plants, the high light stress is associated with increased carotenoid accumulation to prevent photoinhibition in the chloroplast. Most of this increase in carotenoid accumulation in leaves is the result of an increase in $\beta$-carotene with additional increases in unidentified carotenoids (Table 1). There were very few significant differences in accumulation among the other carotenoids. The unidentified carotenoids represented between $12 \%$ and $19 \%$ of the total leaf carotenoid depending on cultivar and light intensity group.

Carotenoid concentrations were markedly decreased in fruit-grown plants cultivated under increased light levels (Fig. 1D). The same trend was observed for all three orangefruited cultivars regardless of total carotenoid accumulation level. In 'Fogo', a cultivar with high total carotenoid accumulation, plants grown under reduced light levels had significant increases in all of the specific carotenoids except lutein (Table 2). The most abundant carotenoid in fruit on shaded 'Fogo' plants was violaxanthin, whereas the most abundant carotenoid in fruit on field-grown plants was lutein. The unidentified pool of carotenoids in 
Table 1. Carotenoid accumulation in leaf tissue of $C$. annuum grown under three different illumination conditions. ${ }^{\mathrm{z}}$

\begin{tabular}{lcccccr}
\hline Cultivar & $\beta$-carotene & $\beta$-cryptoxanthin & Lutein & Zeaxanthin & Violaxanthin & $\begin{array}{r}\text { Unidentified } \\
\text { carotenoids }\end{array}$ \\
\hline Fogo & & & & & & \\
$\quad$ Shaded greenhouse & $38.20 \mathrm{~b}^{\mathrm{y}}$ & $\mathrm{ND}^{\mathrm{x}}$ & $21.35 \mathrm{a}$ & $0.61 \mathrm{a}$ & $1.79 \mathrm{a}$ & $9.02 \mathrm{~b}$ \\
$\quad$ Greenhouse & $48.46 \mathrm{~b}$ & $\mathrm{ND}$ & $24.36 \mathrm{a}$ & $1.06 \mathrm{a}$ & $2.84 \mathrm{a}$ & $11.76 \mathrm{~b}$ \\
$\quad$ Field & $118.60 \mathrm{a}$ & $\mathrm{ND}$ & $22.51 \mathrm{a}$ & $0.68 \mathrm{a}$ & $1.85 \mathrm{a}$ & $34.67 \mathrm{a}$ \\
& & & & & & \\
Orange Grande & & & & & & \\
$\quad$ Shaded greenhouse & $39.29 \mathrm{~b}$ & $0.19 \mathrm{~b}$ & $16.22 \mathrm{c}$ & $7.92 \mathrm{c}$ & $0.21 \mathrm{a}$ & $9.31 \mathrm{c}$ \\
$\quad$ Greenhouse & $46.84 \mathrm{~b}$ & $0.19 \mathrm{~b}$ & $20.59 \mathrm{~b}$ & $10.00 \mathrm{~b}$ & $0.36 \mathrm{a}$ & $12.98 \mathrm{~b}$ \\
Field & $91.60 \mathrm{a}$ & $1.39 \mathrm{a}$ & $23.85 \mathrm{a}$ & $13.46 \mathrm{a}$ & $1.26 \mathrm{a}$ & $20.72 \mathrm{a}$ \\
& & & & & & \\
NuMex Sunset & & & & & & \\
$\quad \begin{array}{l}\text { Shaded greenhouse } \\
\text { Greenhouse }\end{array}$ & $49.42 \mathrm{~b}$ & ND & $16.30 \mathrm{c}$ & $0.88 \mathrm{~b}$ & $2.56 \mathrm{a}$ & $13.22 \mathrm{~b}$ \\
$\quad$ Field & $56.45 \mathrm{~b}$ & ND & $18.27 \mathrm{~b}$ & $1.05 \mathrm{~b}$ & $2.76 \mathrm{a}$ & $14.88 \mathrm{~b}$ \\
\hline
\end{tabular}

${ }^{\mathrm{z}}$ High-performance liquid chromatography was used to quantify pigments expressed as $\mu \mathrm{g} \cdot \mathrm{g}^{-1}$ fresh $\mathrm{wt}$ leaf.

${ }^{\mathrm{y}}$ Mean values $(\mathrm{n}=4)$ within a column for each cultivar followed by different letters are significantly different $(P=0.05)$.

${ }^{\mathrm{x}} \mathrm{ND}=$ not detected.

Table 2. Carotenoid accumulation in fruit pericarp of C. annuum grown under three different illumination conditions. ${ }^{z}$

\begin{tabular}{|c|c|c|c|c|c|c|c|}
\hline Cultivar & $\beta$-carotene & $\beta$-cryptoxanthin & Lutein & Zeaxanthin & Violaxanthin & Capsanthin & $\begin{array}{l}\text { Unidentified } \\
\text { carotenoids }\end{array}$ \\
\hline \multicolumn{8}{|l|}{$\overline{\text { Fogo }}$} \\
\hline $\begin{array}{l}\text { Shaded } \\
\text { greenhouse }\end{array}$ & $11.40 \mathrm{a}^{\mathrm{y}}$ & $5.90 \mathrm{a}$ & $41.29 \mathrm{a}$ & $34.50 \mathrm{a}$ & $83.24 \mathrm{a}$ & $\mathrm{ND}^{\mathrm{x}}$ & $135.22 \mathrm{a}$ \\
\hline Greenhouse & $4.64 \mathrm{~b}$ & $0.60 \mathrm{~b}$ & $43.80 \mathrm{a}$ & $4.52 \mathrm{~b}$ & $22.02 \mathrm{~b}$ & ND & $78.72 \mathrm{~b}$ \\
\hline Field & $4.23 \mathrm{~b}$ & $2.65 \mathrm{~b}$ & $24.59 \mathrm{a}$ & $7.02 \mathrm{~b}$ & $3.99 \mathrm{~b}$ & ND & $54.00 \mathrm{~b}$ \\
\hline \multicolumn{8}{|l|}{ Orange Grande } \\
\hline $\begin{array}{l}\text { Shaded } \\
\text { greenhouse }\end{array}$ & $10.17 \mathrm{a}$ & $4.57 \mathrm{a}$ & $22.46 \mathrm{a}$ & $91.87 \mathrm{a}$ & $3.59 \mathrm{a}$ & ND & $44.57 \mathrm{a}$ \\
\hline Greenhouse & $8.42 \mathrm{~b}$ & $3.24 \mathrm{a}$ & $18.88 \mathrm{~b}$ & $51.20 \mathrm{~b}$ & $2.12 \mathrm{a}$ & ND & $34.71 \mathrm{~b}$ \\
\hline Field & $5.10 \mathrm{~b}$ & $2.78 \mathrm{~b}$ & $13.42 \mathrm{~b}$ & $32.64 \mathrm{c}$ & $1.38 \mathrm{a}$ & ND & $24.77 \mathrm{c}$ \\
\hline \multicolumn{8}{|l|}{ NuMex Sunset } \\
\hline $\begin{array}{l}\text { Shaded } \\
\text { greenhouse }\end{array}$ & ND & ND & ND & ND & ND & $17.97 \mathrm{a}$ & $7.43 \mathrm{a}$ \\
\hline Greenhouse & ND & ND & ND & ND & ND & $11.66 \mathrm{~b}$ & $0.33 \mathrm{~b}$ \\
\hline Field & ND & ND & ND & ND & ND & $8.25 \mathrm{~b}$ & $0.00 \mathrm{~b}$ \\
\hline
\end{tabular}

${ }^{\mathrm{z}}$ High-performance liquid chromatography was used to quantify pigments expressed as $\mu \mathrm{g} \cdot \mathrm{g}^{-1} \mathrm{fresh}$ weight pericarp.

${ }^{\mathrm{y}}$ Mean values $(\mathrm{n}=4)$ within a column for each cultivar followed by different letters are significantly different $(P=0.05)$.

${ }^{\mathrm{x}} \mathrm{ND}=$ not detected

fruit of 'Fogo' grown under any light condition was larger than in any other cultivar and increased in abundance with decreasing light. In 'Orange Grande', a cultivar with high provitamin A carotenoids, plants grown under reduced light levels had significant increases in all of the specific carotenoids. In this cultivar, zeaxanthin was the most abundant carotenoid in fruit regardless of growth conditions. 'NuMex Sunset' is an unusual orange-fruited cultivar that does not accumulate any $\beta$-carotene and has very low levels of carotenoids (Rodriguez-Uribe et al., 2012). Again, fruit on shaded plants of this cultivar had increased levels of capsanthin along with unidentified carotenoids as compared with field-grown plants. Unidentified carotenoid peaks in chromatograms of fruit samples represented between $18 \%$ and $40 \%$ of the total fruit carotenoid depending on cultivar and light intensity group (Table 2).

Russo and Howard (2002) reported cultivarspecific responses among red-fruited pepper cultivars; the majority of cultivars demonstrated an increase in carotenoids in fruit from green house plants compared with the field plants. No orange-colored cultivars as rich sources of pro-vitamin A carotenoids, $\beta$-carotene, and $\beta$-cryptoxanthin were included in their study. The light levels of the two environments were not described, although presumably the greenhouse had reduced light relative to the field.

There is wide cultivar-specific variation in the carotenoid levels of Capsicum fruit. Wall et al. (2001) demonstrated this for $\beta$-carotene [0 to $136 \mu \mathrm{g} \cdot \mathrm{g}^{-1}$ fresh weight $\left.(\mathrm{FW})\right]$ and total carotenoids (4 to $1173 \mu \mathrm{g} \cdot \mathrm{g}^{-1} \mathrm{FW}$ ) across 25 cultivars from three species. Red-colored fruit usually has the highest levels of carotenoids, although there are specific exceptions. There are a few reports that include analyses on yellow- or orange-colored peppers; fruit of these colors usually have lower carotenoid content (Guzmán et al., 2010; Howard et al., 2000; Wall et al., 2001). The three orange-colored cultivars used in this study, 'Fogo', 'Orange Grande', and
'NuMex Sunset', were selected based on our earlier work that demonstrated these cultivars had distinct carotenoid profiles (RodriguezUribe et al., 2012). In that earlier study we reported total carotenoid levels of $\approx 160,90$, and $10 \mu \mathrm{g} \cdot \mathrm{g}^{-1} \mathrm{FW}$ pericarp for 'Fogo', 'Orange Grande', and 'NuMex Sunset', respectively. These carotenoid values are very similar to the levels reported here for field samples of these fruit in Figure 1D. The cultivar-specific carotenoid patterns expected for these samples, based on previous analysis (Rodriguez-Uribe et al., 2012), were observed in the field sources of the three cultivars (Table 2).

Environmental stresses will affect fruit quality; high temperature may increase pungency levels in Capsicum fruit (Lindsay and Bosland, 1995). Here we demonstrate that Capsicum fruit pigment is also responsive to environmental influence, probably light levels. Additional stresses in these environments include water deficiency, high temperature, and wind, particularly in the field. Tomato fruit on a shaded side of trellised field-grown plants have reduced lycopene content relative to the fruit grown in direct sun (Helyes et al., 2007; Pék et al., 2011). This reduction in lycopene content was proposed to be the result of an increased fruit temperature rather than light levels based on the observation that several components of tomato fruit quality are correlated with temperature rather than light levels (Riga et al., 2008). Other work has linked tomato carotenoid content with light quality. Red-light treatment $(30 \mathrm{~min})$ of dark-stored breaker tomatoes increased the lycopene content but not the $\beta$-carotene content in fruit over a 21 d period (Liu et al., 2009). Phytochrome has been proposed as a component of the light regulation of carotenoid accumulation in tomato fruit (Alba et al., 2000; Schofield and Paliyath, 2005).

Increasing levels of fruit carotenoids that have nutritional value for human health by manipulation of the plant growth environment is intriguing. For instance, 'Fogo' and 'Orange Grande' have relatively high amounts of pro-vitamin A carotenoids $\beta$-carotene and $\beta$ cryptoxanthin in fruit with higher levels of these carotenoids in fruit from unshaded greenhouse plants and shaded greenhouse plants. Two other carotenoids, lutein and zeaxanthin, play key roles in vision as macular pigments (Stringham and Hammond, 2005). Again levels of these carotenoids were higher in fruit from shaded 'Fogo' and 'Orange Grande' plants compared with field plants. Capsanthin, the red pigment found in NuMex Sunset cultivar, also accumulated to higher levels in shaded plants compared with the other groups. This pigment has a role in human health by preventing free radical formation and may have cancer prevention effects (Maoka et al., 2001). Although there are many differences between the field and greenhouse settings that could be invoked to explain the differences in fruit carotenoid accumulation, there are very few differences between the shaded and unshaded greenhouse settings besides the reduced light 
levels. Furthermore, a role for light in the accumulation patterns of the chlorophyll and carotenoids in leaf samples is supported by previous reports in pepper (Simkin et al., 2003). Our study did not determine if the different levels of carotenoids in fruit were the result of changes in synthesis or degradation rates; either is possible. However, the basis for the different regulatory responses on the carotenoid pathway in fruit and leaf tissue warrants further study.

\section{Conclusions}

In three $C$. annuum cultivars, leaf carotenoids accumulated to higher levels in plants grown under higher light intensity. Carotenoid levels in fruit from these same plants showed the opposite trend, higher carotenoid levels with lower light intensity level. Carotenoids are antioxidants that are essential for human health; these results suggest that manipulation of the growth environment to increase the nutritional value of fruit may be possible.

\section{Literature Cited}

Alba, R., M.M. Cordonnier-Pratt, and L.H. Pratt. 2000. Fruit-localized phytochromes regulate lycopene accumulation independently of ethylene production in tomatoes. Plant Physiol. 123:363370.

Ames, B.N., M.K. Shigenaga, and T.M. Hagen. 1993. Oxidants, antioxidants, and the degenerative diseases of aging. Proc. Natl. Acad. Sci. USA 90:7915-7922.

Farre, G., G. Sanahuja, S. Naqvi, C. Bai, T. Capell, C. Zhu, and P. Christou. 2010. Travel advice on the road to carotenoids in plants. Plant Sci. 179:28-48.

Guzmán, I., S. Hamby, J. Romero, P.W. Bosland, and M.A. O'Connell. 2010. Variability of carotenoid biosynthesis in orange colored Capsicum spp. Plant Sci. 179:49-59.

Helyes, L., A. Lugasi, and Z. Pék. 2007. Effect of natural light on surface temperature and lycopene content of vine ripened tomato fruit. Can. J. Plant Sci. 87:927-929.
Hornero-Méndez, D., R.G. de Guevara, and M.I. Mínguez-Mosquera. 2000. Carotenoid biosynthesis changes in five red pepper (Capsicum annuит L.) cultivars during ripening. Cultivar selection for breeding. J. Agr. Food Chem. 48:3857-3864.

Howard, L.R., S.T. Talcott, C.H. Brenes, and B. Villalon. 2000. Changes in phytochemical and antioxidant activity of selected pepper cultivars (Capsicum species) as influenced by maturity. J. Agr. Food Chem. 48:1713-1720.

Lee, J.J., K.M. Crosby, L.M. Pike, K.S. Yoo, and D.I. Leskovar. 2005. Impact of genetic and environmental variation on development of flavonoids and carotenoids in pepper (Capsicum spp.). Sci. Hort. 106:341-352.

Lindsay, K. and P.W. Bosland. 1995. A field study of environmental interaction on pungency. Capsicum Eggplant Newsl. 14:36-38.

Liu, L.H., D. Zabras, L.E. Bennett, P. Aguas, and B.W. Woonton. 2009. Effects of UV-C, red light, and sun light on the carotenoid content and physical qualities of tomatoes during postharvest storage. Food Chem. 115:495-500.

Malkin, R.A. and K. Niyogi. 2000. Photosynthesis, p. 568-628. In: Buchanan, B., W. Gruissem, and R. Jones (eds.). Biochemistry and molecular biology of plants. Amer. Soc. Plant Physiol., Rockville, MD.

Maoka, T., K. Mochida, M. Kozuka, Y. Ito, Y. Fujiwara, K. Hashimoto, F. Enjo, M. Ogata, Y. Nobukuni, H. Tokuda, and H. Nishino. 2001. Cancer chemopreventive activity of carotenoids in the fruits of red paprika Capsicum annuum L. Cancer Lett. 172:103-109.

Pék, Z., P. Szuvandzsiev, A. Nemenyi, L. Helyes, and A. Lugasi. 2011. The effect of natural light on changes in antioxidant content and color parameters of vine-ripened tomato (Solanum lycopersicum L.) fruits. HortScience 46:583-585.

Pizarro, L. and C. Stange. 2009. Light-dependent regulation of carotenoid biosynthesis in plants. Cien. Inv. Agr. 36:143-162.

Rao, A.V. and L.G. Rao. 2007. Carotenoids and human health. Pharmacol. Res. 55:207-216.

Richins, R.D., L. Hernandez, B. Dungan, S. Hamby, F.O. Holguín, and M.A. O'Connell. 2010. A 'green' extraction protocol to recover red pigments from hot Capsicum fruit. HortScience 45:1084-1087.
Riga, P., M. Anza, and C. Garbisu. 2008. Tomato quality is more dependent on temperature than on photosynthetically active radiation. J. Sci. Food Agr. 88:158-166.

Rodriguez-Uribe, L., I. Guzmán, W. Rajapakse, R.D. Richins, and M.A. O'Connell. 2012. Carotenoid accumulation in orange-pigmented Capsicum аппиит fruit, regulated at multiple levels. J. Expt. Bot. 63:517-526.

Russo, V.M. and L.R. Howard. 2002. Carotenoids in pungent and non-pungent peppers at various developmental stages grown in the field and glasshouse. J. Sci. Food Agr. 82: 615-624.

Schofield, A. and G. Paliyath. 2005. Modulation of carotenoid biosynthesis during tomato fruit ripening through phytochrome regulation of phytoene synthase activity. Plant Physiol. Biochem. 43:1052-1060.

Simkin, A.J., C. Zhu, M. Kuntz, and G. Sandmann. 2003. Light-dark regulation of carotenoid biosynthesis in pepper (Capsicum annuum) leaves. J. Plant Physiol. 160:439-443.

Stringham, J.M. and B.R. Hammond. 2005. Dietary lutein and zeaxanthin: Possible effects on visual function. Nutr. Rev. 63:59-64.

Valko, M., D. Leibfritz, J. Moncol, M.T.D. Cronin, M. Mazur, and J. Telser. 2007. Free radicals and antioxidants in normal physiological functions and human disease. Intl. J. Biochem. Cell Biol. 39:44-84.

Wahyuni, Y., A.R. Ballester, E. Sudarmonowati, R.J. Bino, and A.G. Bovy. 2011. Metabolite diversity in pepper (Capsicum) fruits for thirtytwo diverse accessions: Variation in health related compounds and implications for breeding. Phytochemistry $72: 1358-1370$.

Wall, M.M. and P.W. Bosland. 1998. Analytical methods for color and pungency of chiles (capsicums), p. 347-373. In: Wetzel, D. and G. Charalambous (eds.). Instrumental methods in food and beverage analysis. Elsevier Science Amsterdam, The Netherlands.

Wall, M.M., C.A. Waddell, and P.W. Bosland 2001. Variation in $\beta$-carotene and total carotenoid content in fruits of Capsicum. HortScience 36:746-749.

Yeum, K.J. and R.M. Russell. 2002. Carotenoid bioavailability and bioconversion. Annu. Rev. Nutr. 22:483-504. 